\title{
Self-Organizing Growth of $\mathrm{MgAl}_{2} \mathrm{O}_{4}$ Based Heterostructural Nanochains
}

\author{
Yong Zhang, ${ }^{\dagger}$ Ruying Li, ${ }^{\dagger}$ Xiaorong Zhou, ${ }^{\ddagger}$ Mei Cai, ${ }^{\S}$ and Xueliang Sun*,, \\ Department of Mechanical and Materials Engineering, University of Western Ontario, London, Ontario, \\ Canada N6A 5B9, School of Materials, The University of Manchester, Manchester M60 1QD, U.K., and \\ General Motors Research and Development Center, Warren, Michigan 48090-9055
}

Received: February 18, 2008; Revised Manuscript Received: April 14, 2008

\begin{abstract}
Heterostructural nanochains consisting of crystalline spinel $\mathrm{MgAl}_{2} \mathrm{O}_{4}$ "nanowires" and amorphous compound oxide "nanobeads" have been synthesized via a simple chemical vapor deposition process. Introduction of methanol is found to play a key role in the generation of the chainlike structure. The regularly spaced nanobeads are obtained on the surface of the spinel nanowires with the introduction of methanol, while only random nanoparticles are observed on the nanowires without methanol. A two-step self-organizing growth model has been proposed. Deep understanding of this distinct chainlike heterostructure is expected to promote the development of novel electrical, optical, and selective catalytic nanodevices.
\end{abstract}

\section{Introduction}

The bottom-up engineering approach makes it possible to link the nanoscale world of nanowires to the macroscopic world of conventional integrated circuits. Different kinds of nanowires have attracted steadily increasing interest due to their unique role in acting as both functional units and interconnects between the units. Compared to homogeneously structured nanowires, heterostructured nanowires promise further degrees of freedom associated with the shape of each segment as well as the coupling between different layers. This kind of structure will enable diverse and additive functionalities if their compositions, shapes, and structures are carefully controlled. Aside from various compositionally modulated nanowires with the same diameter, ${ }^{1-10}$ diameter-modulated nanowires (so-called "nanochains") have been rarely reported. Recently, some homo- and heterojunctional chainlike structures including silicon, ${ }^{11,12}$ silica/ silicon, ${ }^{13}$ silicon carbide, ${ }^{14,15}$ tin oxide, ${ }^{16}$ boron, ${ }^{17}$ indium oxide/ tin oxide, ${ }^{18}$ and gold ${ }^{19}$ nanochains and microchains have been developed. In addition, the physical and chemical properties exhibited by the chainlike one-dimensional nanostructures have shown their potential applications for developing light emitting diodes, ${ }^{20}$ electrochemical nanodevices, ${ }^{21}$ and single-electron and optoelectronic devices. ${ }^{22}$ To further exploit the potential and possibilities of this distinct structure, it is essential to develop nanochains with novel hybrid material.

As an attractive class of composite metal oxides, spinel oxides $\left(\mathrm{AB}_{2} \mathrm{O}_{4}\right.$, where $\mathrm{A}$ and $\mathrm{B}$ are bivalent and trivalent, respectively) have been widely used due to their improved reactivity compared to the corresponding single oxides ${ }^{23}$ and due to excellent electrical as well as magnetic properties, which promise wide technological applications. Recently, some research work has been done on one-dimensional spinel oxides. ${ }^{24-29}$ As a typical spinel oxide, some intriguing properties of $\mathrm{MgAl}_{2} \mathrm{O}_{4}$ have been reported, such as distinct electrical properties, ${ }^{30}$ excellent luminescence, ${ }^{31}$ and high hydrothermal stability. ${ }^{32}$ In this paper, we report successful preparation of $\mathrm{MgAl}_{2} \mathrm{O}_{4}$ based $\mathrm{Mg}-\mathrm{Al}-\mathrm{Si}$ oxide heterostructural nanochains via self-organiz-

\footnotetext{
* To whom correspondence should be addressed. E-mail: xsun@eng.uwo.ca.

$\dagger$ University of Western Ontario.

\$ The University of Manchester.

$\S$ General Motors Research and Development Center.
}

ing growth using an easily controlled chemical vapor deposition method. These oxide based nanochains are expected to find their potential applications in developing tunable one-dimensional humidity sensors, ${ }^{30}$ solid-state lasers, ${ }^{31}$ catalysts or catalyst supports, ${ }^{32}$ and other nanodevices.

\section{Experimental Procedures}

The oxide nanochains were fabricated in a hot-wall chemical vapor deposition (HWCVD) system under ambient pressure. An alumina tube (outer diameter, 2 in.; length, 48 in.) was mounted horizontally inside the furnace, where temperature, flow rate, and reaction time were controlled. A cordierite $\left(2 \mathrm{MgO}-2 \mathrm{Al}_{2} \mathrm{O}_{3}-5 \mathrm{SiO}_{2}\right)$ sheet (total impurity $\mathrm{K}, \mathrm{Ca}$, $\mathrm{Na}, \mathrm{Sn}, \mathrm{Fe} \leq 2$ wt $\%$ ) loaded with aluminum powder was used as the starting material. A carrier gas of high-purity argon (99.999\%) was passed through the tube at a rate of 400 $\mathrm{cm}^{3}$ (STP) $\mathrm{min}^{-1}$ for $30 \mathrm{~min}$ to purge oxygen from the furnace. The furnace was then heated to $1250{ }^{\circ} \mathrm{C}$ for $1 \mathrm{~h}$ at the Ar flow rate of $200 \mathrm{~cm}^{3}$ (STP) $\mathrm{min}^{-1}$. A controlled amount of methanol vapor was introduced by a separate flow of argon gas passing through a methanol bubbler (Ar/methanol) during the reaction process. The flow rate of $\mathrm{Ar} /$ methanol was modulated from 0 to $85 \mathrm{~cm}^{3}(\mathrm{STP}) \mathrm{min}^{-1}$ in our experiments. The furnace was finally cooled to room temperature in the flowing carrier gas.

White featherlike products were collected from the inner wall of the alumina boat container after each experiment. The samples were characterized using Hitachi scanning electron microscopy, Tecnai F30 and JEOL 2010 transmission electron microscopes.

\section{Results and Discussion}

Morphological and Structural Characterization. SEM images of the products grown at $1250{ }^{\circ} \mathrm{C}$ with the $\mathrm{Ar} /$ methanol flow rate of $40 \mathrm{~cm}^{3}(\mathrm{STP}) \mathrm{min}^{-1}$ are shown in Figure 1. Highyield nanochains are observed in Figure 1a. Parts b and $c$ of Figure 1 exhibit regularly spaced nanobead/nanowire structure of over $200 \mu \mathrm{m}$ in length. The diameter of most of the nanowires are around $100 \mathrm{~nm}$, and the diameter of most of the nanobeads are about $200-500 \mathrm{~nm}$. The distance between the nanobeads varies but generally is comparable to the diameter of the nanobeads. Figure 1d shows a higher magnification image of a single nanowire. The diameter of the nanowire is uniform, and 


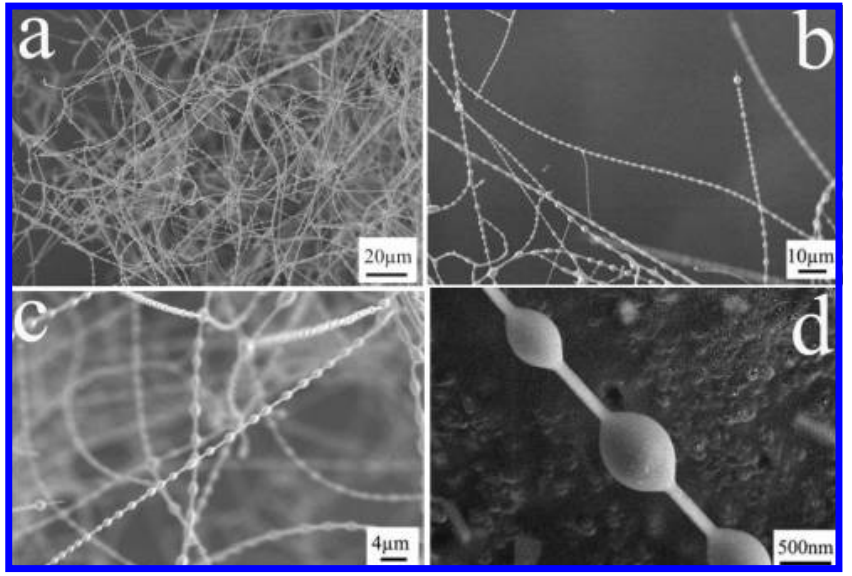

Figure 1. SEM images of the high-density of nanochains at different magnifications.

the surface of the nanobead is smooth. In addition, we examined tens of nanochains and observed no particles at the tip of the nanowire. This differs from the vapor-liquid-solid (VLS) growth mechanism proposed in previous reports, ${ }^{11-17}$ and we will discuss it in detail later on.

Figure 2 shows TEM images, energy-dispersive X-ray (EDX) spectra, and selected area electron diffraction patterns for the structural and compositional analysis of the nanochains. Figure 2a reveals the general morphology of a single nanochain. Parts $\mathrm{b}$ and $\mathrm{c}$ of Figure 2 show the bright- and dark-field TEM images of a single nanobead, respectively. It is revealed that the diameter of a single nanochain exhibits regular fluctuation along the axial direction. The nanochain consists of the nanobeads with a diameter of about $300 \mathrm{~nm}$, and a nanowire with a diameter of $100 \mathrm{~nm}$, which is consistent with the SEM observation. To shed further light on the phase difference between the two areas indicated by " 1 " and " 2 " in Figure 2b, selective area diffraction patterns were performed on the "wire" and "bead" parts, respectively. As shown in Figure 2d, the diffraction pattern of the wire can be indexed to (311), (4⿳亠丷厂2), and (1 $\overline{3} 1)$ crystal planes of the cubic $\mathrm{MgAl}_{2} \mathrm{O}_{4}$ structure. In the diffraction pattern of the nanobead part as shown in Figure 2e, one can see two phase structures with crystalline diffraction spots and a broadened diffraction ring, respectively, revealing the coexistence of crystalline and amorphous structures. The crystalline structure can be assigned to the same $\mathrm{MgAl}_{2} \mathrm{O}_{4}$ phase as that of the nanowire, and the corresponding diffraction pattern can be indexed to (111), (311), and (220) planes of cubic $\mathrm{MgAl}_{2} \mathrm{O}_{4}$, respectively. This suggests that the nanobead part seems to be a combination of the crystalline $\mathrm{MgAl}_{2} \mathrm{O}_{4}$ wire core and an amorphous bead shell, which will be discussed in detail later. In addition, the obvious black-white contrast of the dark-field image, as shown in Figure 2c, also indicates the evident compositional difference between the nanowire part and the nanobead part. EDX spectra taken from the areas marked 1 and 2 in Figure 2c are shown in Figure 2f,g, respectively. As shown in Figure 2f, strong $\mathrm{Al}, \mathrm{O}$, and $\mathrm{Mg}$ signals along with a relatively weak Si signal were detected from the nanowire area. Besides the copper peak from the TEM grid, very weak Fe and Sn peaks were also detected, which comes from the coordinate substrate. The atomic ratio of $\mathrm{Mg}: \mathrm{Al}: \mathrm{O}$ is near 1:2:4, which conforms to the stoichiometry of the $\mathrm{MgAl}_{2} \mathrm{O}_{4}$ phase. While the electron probe was shifted to the nanobead part as shown in Figure $2 \mathrm{~g}$, besides the presence of $\mathrm{Al}, \mathrm{O}$, and $\mathrm{Mg}$ elements, a significant increase of the Si signal was detected, which is different from that of the nanowire part. The detected atomic ratio of $\mathrm{Mg}: \mathrm{Al}$ :

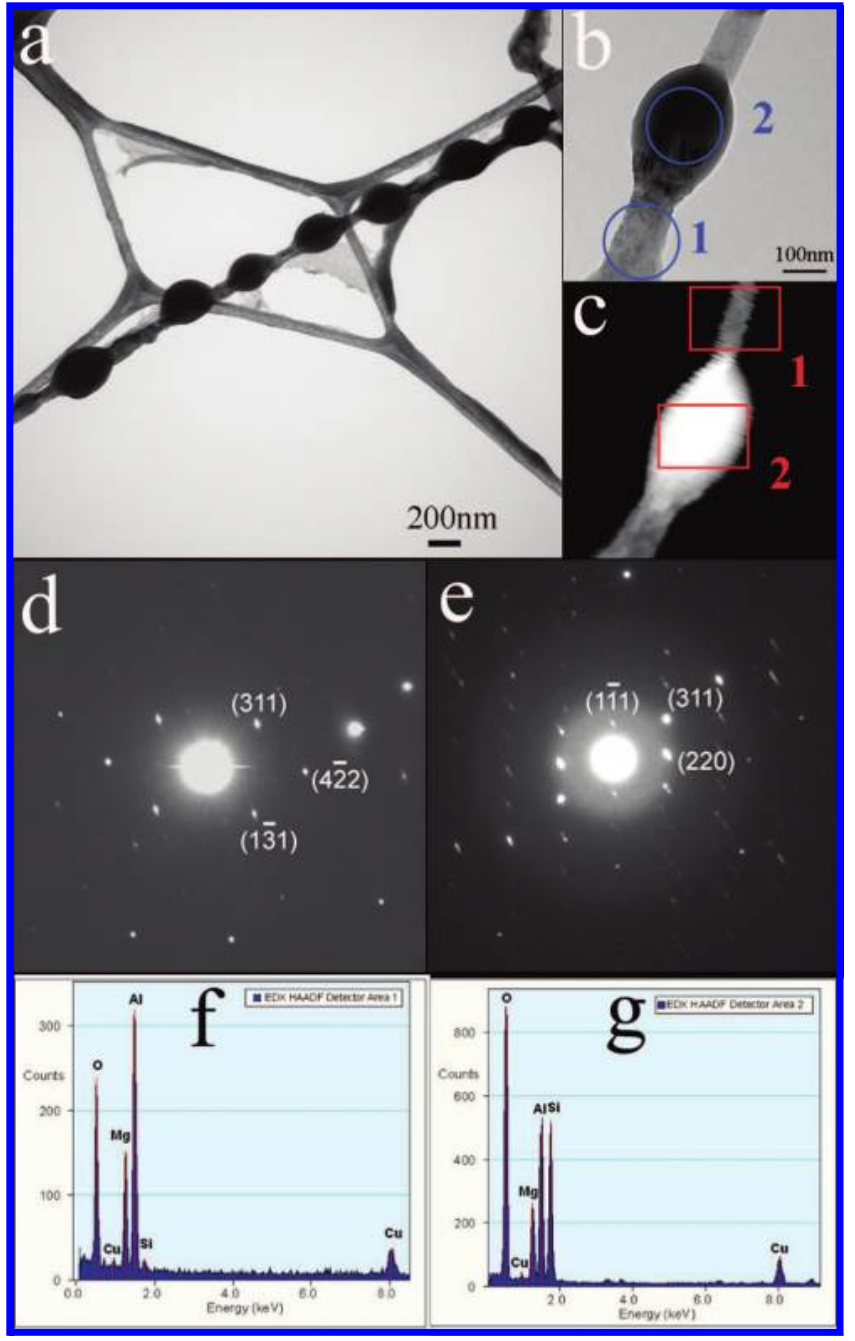

Figure 2. Bright- and dark-field TEM images of a freestanding nanochain and corresponding diffraction pattern and EDX of the wire part and bead part. (a) Bright-field, low-magnification TEM image of a single nanochain, (b) high-magnification bright field and (c) dark field image of the nanobead and nanowire parts, (d) selected area diffraction pattern of area 1 in b, (e) selected area diffraction pattern of area 2 in b, (f) EDX spectrum of area 1 in c, and (g) EDX spectrum of area 2 in $\mathrm{c}$.

$\mathrm{Si}$ :O is approximately $1: 1.6: 1.6: 6.7$. Provided that the nanobead is composed of an $\mathrm{MgAl}_{2} \mathrm{O}_{4}$ core and amorphous shell, the atomic ratio of $\mathrm{Mg}: \mathrm{Al}: \mathrm{Si}: \mathrm{O}$ in the shell is calculated to be 1:1.2: 3.2:9.4.

Role of Methanol. During our experiments, it has been found that methanol plays an important role in generating the chainlike structure. To obtain insight into the role that methanol plays, some controlled experiments have also been carried out to investigate the correlations between the nanochain morphology and the amount of the methanol introduced. As shown in Figure 3 , when no methanol was used, the morphology of the product was exhibited mainly as nanoparticle-coated nanowires (Figure 3a); only a few sparsely distributed nanochains were observed. Figure 3a' shows the corresponding TEM image of the sample shown in Figure 3a. The size of the particles is $100-150 \mathrm{~nm}$ in diameter. EDX results indicated that the particles contained high silicon content. At an Ar/methanol flow rate of $15 \mathrm{~cm}^{3}$ (STP) $\min ^{-1}$, closely distributed nanobeads were observed on the nanowire as shown in Figure 3b. When the Ar/methanol flow rate was increased to $40 \mathrm{~cm}^{3}(\mathrm{STP}) \mathrm{min}^{-1}$ (the same rate which produced the results shown in Figure 1), nanowires with 


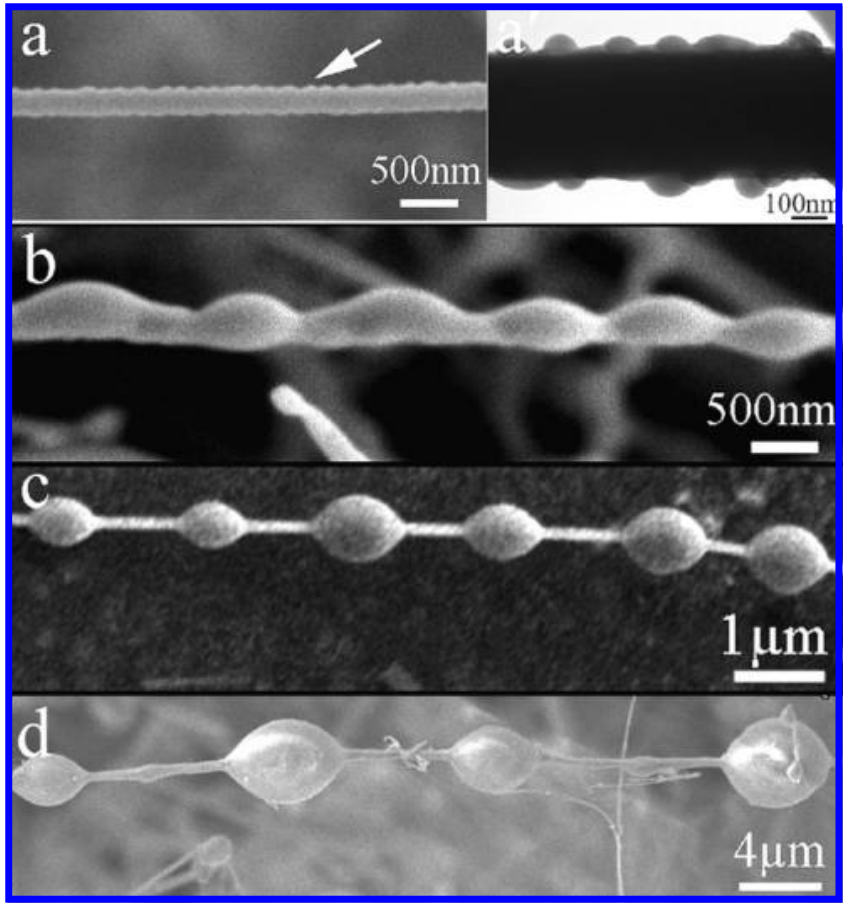

Figure 3. Morphology dependence of nanochains on methanol: (a) SEM image and ( $\left.a^{\prime}\right)$ TEM image of the nanowire before introducing methanol; SEM images of the nanochains with the Ar/methanol flow rates of (b) 15, (c) 40, and (d) $60 \mathrm{sccm}$, respectively.

regularly spaced nanobeads were achieved, as shown in Figure $3 \mathrm{c}$. However, it seemed that introducing a greater amount of methanol resulted in a significantly decreased yield of the nanochains. When the Ar/methanol flow rate of $60 \mathrm{~cm}^{3}$ (STP) $\min ^{-1}$ was applied, some nanobeads were still observed on different nanowires, but the distance between the beads increased obviously. Moreover, the diameters of the nanobeads were less uniform, and the distribution was less regular, as shown in Figure $3 \mathrm{~d}$. Even though it was implied that the diameter of the nanobeads tends to grow bigger with increased argon flow rate, further increasing the Ar/methanol flow rate up to $85 \mathrm{~cm}^{3}$ (STP) $\mathrm{min}^{-1}$ resulted in the disappearance of nanochains; only microwires (not shown) were observed.

Growth Mechanism. Our TEM and EDX investigation implies that nanochains are obtained when heterostructural growth of amorphous nanobeads with high silicon content occurs on the crystalline $\mathrm{MgAl}_{2} \mathrm{O}_{4}$ nanowires. Furthermore, it is the introduction of methanol which induces the formation of the amorphous nanobeads. Figure $4 \mathrm{a}$ shows a close-up view of the TEM image of a typical nanochain. Evidence of an extended meniscus can be observed at the interface between the nanobead and the nanowire, revealing adhesive wetting. Figure $4 \mathrm{~b}$ shows the HRTEM image at the interface between the nanowire and the nanobead, revealing that the single crystalline nanowire is sheathed with an amorphous layer. The lattice spacing of 0.23 $\mathrm{nm}$ corresponds to the $d$ value of (222) lattice fringes of spinel $\mathrm{MgAl}_{2} \mathrm{O}_{4}$. As shown in Figure 4c, the nanobeads resemble dew droplets clinging to the branches, suggesting that the nanobeads have a liquid precursor.

It is interesting to address the growth mechanism of the nanochains. A vapor-liquid-solid (VLS) mechanism has been proposed to explain the growth of nanochains while a catalyst was employed. ${ }^{11-17}$ However, it is not applicable for the growth of nanochains in our case because no catalyst was found at the tip of the nanochains. Due to the key influence of methanol on the product morphology, we believe that the generation of

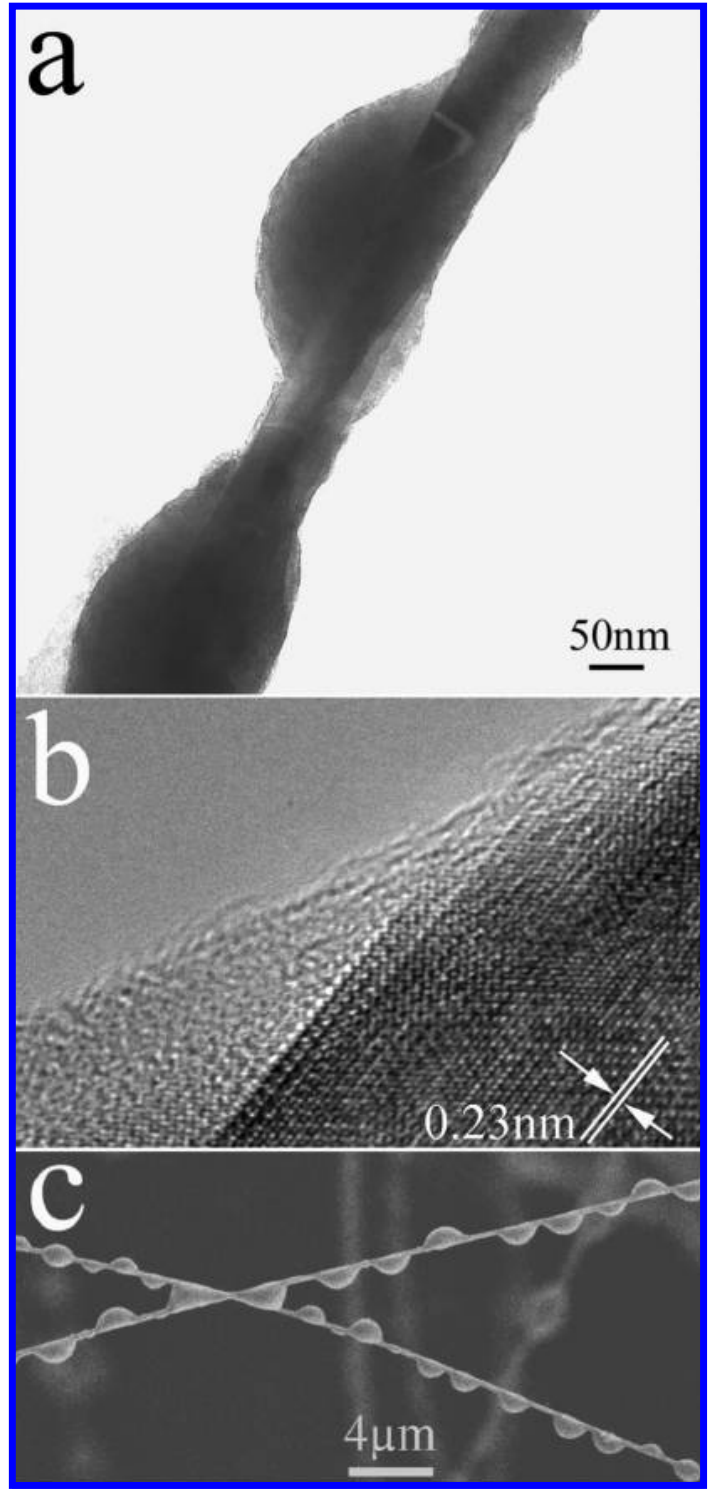

Figure 4. (a) Close-up view of the TEM image, (b) HRTEM image, and (c) SEM image of the nanochains revealing adhesive wetting.

nanochains is associated with the change of vapor pressure ratio caused by gaseous elements involved in the reactions as described in detail below.

At the reaction temperature of $1250{ }^{\circ} \mathrm{C}$, due to the low melting point of metallic aluminum $\left(660^{\circ} \mathrm{C}\right)$, vaporized aluminum would react with the oxide components contained in the cordierite substrate $\left(2 \mathrm{MgO}-2 \mathrm{Al}_{2} \mathrm{O}_{3}-5 \mathrm{SiO}_{2}\right)$, respectively, and the following reactions may be involved: ${ }^{33-37}$

$$
\begin{aligned}
& 4 \mathrm{Al}(\mathrm{g})+\mathrm{Al}_{2} \mathrm{O}_{3}(\mathrm{~s})=3 \mathrm{Al}_{2} \mathrm{O}(\mathrm{g}) \quad \Delta G=-142.18 \mathrm{~kJ} / \mathrm{mol} \quad(1) \\
& 4 \mathrm{Al}(\mathrm{g})+\mathrm{SiO}_{2}(\mathrm{~s})=2 \mathrm{Al}_{2} \mathrm{O}(\mathrm{g})+\mathrm{Si}(\mathrm{s}) \\
& \Delta G=-250.86 \mathrm{~kJ} / \mathrm{mol} \\
& \mathrm{Al}(\mathrm{g})+2 \mathrm{MgO}(\mathrm{s})={ }^{3} /{ }_{2} \mathrm{Mg}(\mathrm{g})+1 / 2 \mathrm{MgO} \cdot \mathrm{Al}_{2} \mathrm{O}_{3}(\mathrm{~s}) \\
& \Delta G=-247.366 \mathrm{~kJ} / \mathrm{mol}(3) \\
& \mathrm{Al}_{2} \mathrm{O}(\mathrm{g})+\mathrm{O}_{2}(\mathrm{~g})=\mathrm{Al}_{2} \mathrm{O}_{3}(\mathrm{~s}) \quad \Delta G=-928.89 \mathrm{~kJ} / \mathrm{mol} \\
& 4 \mathrm{Al}(\mathrm{l})+3 \mathrm{O}_{2}=2 \mathrm{Al}_{2} \mathrm{O}_{3}(\mathrm{~s}) \\
& \Delta G=-1663.90 \mathrm{~kJ} / \mathrm{mol}(5) \\
& 2 \mathrm{Mg}(\mathrm{g})+\mathrm{O}_{2}(\mathrm{~g})=2 \mathrm{MgO}(\mathrm{s}) \quad \Delta G=-866.23 \mathrm{~kJ} / \mathrm{mol}
\end{aligned}
$$




$$
\begin{aligned}
2 \mathrm{Al}_{2} \mathrm{O}(\mathrm{g})+2 \mathrm{Mg}(\mathrm{g})+3 \mathrm{O}_{2}(\mathrm{~g})= & 2 \mathrm{MgAl}_{2} \mathrm{O}_{4} \\
& \Delta G=-2770.33 \mathrm{~kJ} / \mathrm{mol}(7)
\end{aligned}
$$

Under the reaction temperature of our experiments, methanol decomposed into carbon monoxide and hydrogen, which decreased the oxygen partial pressure inside the chamber and made it possible to produce some regions with extremely low oxygen content depending on the local concentration of the formed carbon monoxide and hydrogen. According to the thermodynamic data shown above, $\mathrm{Al}_{2} \mathrm{O}$ vapor with high partial pressure more readily combines with the gaseous magnesium (boiling point, $1090^{\circ} \mathrm{C}$ ) and the residual oxygen in the reaction chamber to produce $\mathrm{MgAl}_{2} \mathrm{O}_{4}$ nanowires due to the strong chemical driving force of forming $\mathrm{MgAl}_{2} \mathrm{O}_{4}$, which restrains the formation of other oxides. Here we ascribe the growth of $\mathrm{MgAl}_{2} \mathrm{O}_{4}$ nanowires to the vapor-solid (VS) mechanism, in which the degree of vapor supersaturation has been generally accepted as a prime growth driving force. ${ }^{38,39}$ Simultaneously, as shown in reaction 2 , solid silicon was generated. The formed silicon was dissolved in the liquid aluminum and generated vaporized silicon species. As the growth proceeded, the vapor pressure of the silicon kept growing. In this case, the vaporized $\mathrm{Si}, \mathrm{Al}$, and $\mathrm{Mg}$ species would absorb on the surface of the obtained $\mathrm{MgAl}_{2} \mathrm{O}_{4}$ nanowires and tend to form a shell. When methanol was not introduced, the vaporized species may be readily oxidized into small oxide nanoparticles as shown in Figure 3a. When methanol was introduced, the oxygen content was decreased in the chamber. In terms of the composition of the amorphous bead shell, EDX analysis showed that the element ratio of $\mathrm{Mg}: \mathrm{Al}: \mathrm{Si}$ at the reaction temperature is 1:1.2: 3.2. On the basis of the $\mathrm{Mg}-\mathrm{Al}-\mathrm{Si}$ trinary-phase diagram, ${ }^{40} \mathrm{a}$ layer of liquid $\mathrm{Mg}-\mathrm{Al}-\mathrm{Si}$ alloy could be formed on the $\mathrm{MgAl}_{2} \mathrm{O}_{4}$ nanowire (Figure 5a) under the condition that oxidization of the gaseous $\mathrm{Mg}, \mathrm{Al}$, and $\mathrm{Si}$ species was temporarily restrained due to the presence of reducing agents. As the growth time proceeded, the thickness and length of the liquid alloy layer increased (Figure 5b). Due to Rayleigh instability, ${ }^{41}$ driven by surface tension, the liquid alloy layer would tend to minimize its surface free energy by forming the shape of a sphere (Figure 5 c). With the proceeding of the $\mathrm{MgAl}_{2} \mathrm{O}_{4}$ nanowire growth, the process of forming a liquid layer, leading to a liquid sphere

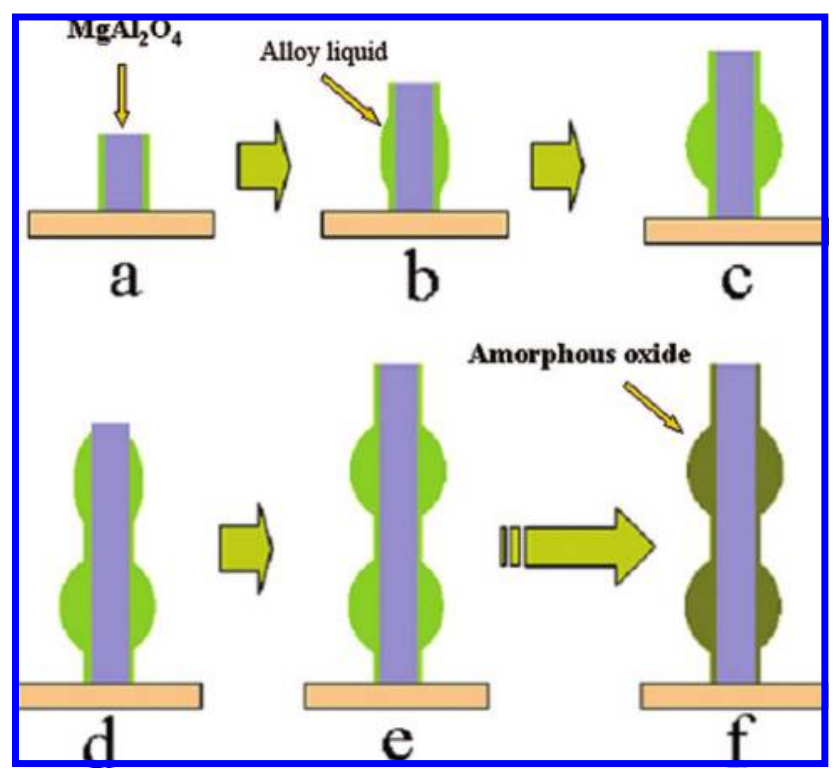

Figure 5. Schematic diagrams of the growth process of the nanochains. continued (Figure 5d,e). The regularly distributed nanobeads are expected to be formed through a self-organizing process. Subsequently, it is possible that the liquid sphere could slowly absorb the oxygen species inside the chamber, until the oxygen content inside the liquid sphere reached a supersaturated level. Eventually, amorphous $\mathrm{Mg}-\mathrm{Al}-\mathrm{O}-\mathrm{Si}$ nanobeads were formed on the surface of the $\mathrm{Mg}-\mathrm{Al}-\mathrm{O}-\mathrm{Si}$ nanowires (Figure 5f). At this point, heterostructural nanochains have formed. During the shrinking process of the liquid alloy, a thin layer of liquid might remain on the wire surface, and it was oxidized into a thin oxide layer. This is the reason why the amorphous layer was also present on the surface of the nanowires, as shown in Figure 4a.

To confirm our assumption of the growth mechanism, we also introduced hydrogen instead of methanol in other experiment. The result indicated that the chainlike structure was also triggered by the introduction of hydrogen but with much bigger size and with the uniformity of the nanobeads being relatively harder to control. It indicates that a weak oxygen environment may favor the formation of uniform nanochains in this case. As we try to understand the growth process, the concentration changes of oxygen and all other gaseous reactants should be considered. The changes may control the nanowires growth rate $^{42}$ as well as tune the viscosity of the alloy liquid, which consequently affect the morphology of the final product. Further investigation of the nanochain growth mechanism is still underway.

\section{Conclusions}

We have developed a simple route to synthesize heterostructural nanochains consisting of crystalline $\mathrm{MgAl}_{2} \mathrm{O}_{4}$ nanowires and amorphous $(\mathrm{Mg}, \mathrm{Al}, \mathrm{Si})$ oxide nanobeads via the chemical vapor deposition method. The resultant chainlike nanostructures are over $200 \mu \mathrm{m}$ long and consist of regular nanobeads with diameters of $200-500 \mathrm{~nm}$, and nanowires of about $100 \mathrm{~nm}$ in diameter. The morphology of nanochains are related to the amount of methanol introduced. Morphology observations and composition analysis reveal a two-step growth process of the nanochains. The growth model proposes that a self-organizing process may explain the regularly alternating distribution of the thicker "nanobeads" and thinner "nanowires" along the axial direction. The heterostructured nanochains with controllable morphological variation may promote the development of new types of nanodevices and nanosystems.

Acknowledgment. This research was supported by General Motors of Canada, the Natural Sciences and Engineering Research Council of Canada (NSERC), the NSERC Canada Research Chair (CRC) Program, the Canada Foundation for Innovation (CFI), the Ontario Research Fund (ORF), the Ontario Early Researcher Award (ERA), and The University of Western Ontario.

\section{References and Notes}

(1) Hu, J. T.; Ouyang, M.; Yang, P. D.; Lieber, C. M. Nature 1999, $399,48$.

(2) Gudiksen, M. S.; Lauhon, L. J.; Wang, J. F.; Smith, D. C.; Lieber, C. M. Nature 2002, 415, 617 .

(3) Wu, Y. Y.; Fan, R.; Yang, P. D. Nano Lett. 2002, 2, 83.

(4) Bjolrk, M. T.; Ohlsson, B. J.; Sass, T.; Persson, A. I.; Thelander, C.; Magnusson, M. H.; Deppert, K.; Wallenberg, L. R.; Samuelson, L. Nano Lett. 2002, 2, 87.

(5) Park, W. I.; Yi, G.-C.; Kim, M.; Pennycook, S. J. Adv. Mater. 2003, $15,526$.

(6) Xue, F. H.; Fei, G. T.; Wu, B.; Cui, P.; Zhang, L. D. J. Am. Chem. Soc. 2005, 127, 15348.

(7) Salem, A. K.; Chao, J.; Leong, K. V.; Searson, P. C. Adv. Mater. 2004, 16, 268. 
(8) Choi, J.; Oh, S. J.; Ju, H.; Cheon, J. Nano Lett. 2005, 5, 2179.

(9) Piraux, L.; George, J. M.; Despres, J. F.; Leroy, C.; Ferain, E.; Legras, R.; Ounadjela, K.; Fert, A. Appl. Phvs. Lett. 1994, 65, 2484.

(10) Nicewarner-Peña, S. R.; Freeman, R. G.; Reiss, B. D.; He, L.; Peña, D. J.; Walton, I. D.; Cromer, R.; Keating, C. D.; Natan, M. J. Science 2001, 294, 137.

(11) Kohno, H.; Takeda, S. Appl. Phys. Lett. 1998, 73, 3144.

(12) Barsotti, R. J.; Fischer, J. E.; Lee, C. H.; Mahmood, J.; Adu,

C. K. W.; Eklund, P. C. Appl. Phys. Lett. 2002, 81, 2866.

(13) Kolb, F. M.; Hofmeister, H.; Zacharias, M.; Gösele, U. Appl. Phvs. A: Mater. Sci. Process. 2005, 80, 1405.

(14) Hao, Y. J.; Wagner, J. B.; Su, D. S.; Jin, G. Q.; Guo, X. Y. Nanotechnology 2006, 17, 2870

(15) Kohno, H.; Yoshida, H. Phys. Rev. E 2004, 70, 062601.

(16) Lilach, Y.; Zhang, J. P.; Moskovits, M.; Kolmakov, A. Nano Lett. 2005, 5, 2019 .

(17) Yang, Q.; Sha, J.; Wang, L.; Su, Z.; Ma, X.; Wang, J.; Yang, D. J. Mater. Sci. 2006, $41,3547$.

(18) Wang, J. X.; Chen, H. Y.; Gao, Y.; Liu, D. F.; Song, L.; Zhang,

Z. X.; Zhao, X. W.; Dou, X. Y.; Luo, S. D.; Zhou, W. Y.; Wang, G.; Xie,

S. S. J. Cryst. Growth 2005, 284, 73.

(19) Matthias, S.; Schilling, J.; Nielsch, K.; Müller, F.; Wehrspohn, R. B.; Gösele, U. Adv. Mater. 2002, 14, 1618

(20) Huang, L. S.; Wright, S.; Yang, S. G.; Shen, D. Z.; Gu, B. X.; Du,

Y. W. J. Phys. Chem. B 2004, 108, 19901.

(21) Dong-Wan Kim, D. W.; Hwang, I. S.; Kwon, J.; Kang, H. Y.; Park, K. S.; Choi, Y. J.; Choi, K. J.; Jae-Gwan Park, J. G. Nano Lett. 2007, 7, 3041.

(22) Kohno, H.; Takeda, S. J. Surf. Sci. Nanotechnol. 2005, 3, 131.

(23) Wohlfarth, E. P.; Ferromagnetic Materials; North-Holland: Amsterdam, 1982

(24) Fan, H. J.; Knez, M.; Scholz, R.; Nielsch, K.; Pippel, E.; Hesse, D.; Zacharias, M.; Gösele, U. Nat. Mater. 2006, 5, 627.
(25) Wang, D.; Chu, X. F.; Gong, M. L. Nanotechnology 2006, 17, 5501.

(26) Fan, H. J.; Knez, M.; Scholz, R.; Hesse, D.; Nielsch, K.; Zacharias, M.; Gösele, U. Nano Lett. 2007, 7, 993.

(27) Yang, Y.; Sun, X. W.; Tay, B. K.; Wang, J. X.; Dong, Z. L.; Fan, H. M. Adv. Mater. 2007, 19, 1839.

(28) Wang, L. S.; Zhang, X. Z.; Liao, X.; Yang, W. G. Nanotechnology 2005, 16, 2928.

(29) Hua, Z. H.; Chen, R. S.; Li, C. L.; Yang, S. G.; Lu, M.; Gu, B. X.; Du, Y. W. J. Alloys Compd. 2007, 427, 199.

(30) Gusmano, G.; Montesperelli, G.; Traversa, E. J. Am. Ceram. Soc. 1993, 76, 743 .

(31) Singha, V.; Chakradharb, R. P. S.; Raoc, J. L.; Kim, D. K. $\underline{\text { J. Solid }}$ State Chem. 2007, 80, 2067.

(32) Li, W. C.; Comotti, M.; Lu, A. H.; Schüth, F. Chem. Commun. (Cambridge) 2006, 1772.

(33) Brewer, L.; Searcy, A. W. J. Am. Chem. Soc. 1951, 73, 5308.

(34) Hoch, M.; Johnston, H. L. J. Am. Chem. Soc. 1954, 76, 2560.

(35) Prabriputaloong, K.; Piggott, M. R. J. Electrochem. Soc.: SolidState Sci. Technol. 1974, 121, 432.

(36) Hong, L.; Okumura, K.; Sano, M. Metall. Mater. Trans. B 1999, $30,1003$.

(37) NASA Thermo Build, http://cea.grc.nasa.gov.

(38) Zhai, T. Y.; Zhong, H. Z.; Gu, Z. J.; Peng, A. D.; Fu, H. B.; Ma, Y.; Li, Y. F.; Yao, J. N. J. Phvs. Chem. C 2007, 111, 2980.

(39) Wang, Z. Y.; Lu, Q. F.; Fang, X. S.; Tian, X. K.; Zhang, L. D. Adv. Funct. Mater. 2006, 16, 661.

(40) Lacaze, J.; Valdes, R. Monatsh. Chem. 2005, 136, 1899.

(41) de Heer, W. A.; Poncharal, P.; Berger, C.; Gezo, J.; Song, Z.; Bettini, J.; Ugarte, D. Science 2005, 307, 907.

(42) Park, J. H.; Choi, Y. J.; Park, J. G. J. Crust. Growth 2005, 280, 161.

JP801439R 